\title{
Cyclin B
}

National Cancer Institute

\section{Source}

National Cancer Institute. Cyclin B. NCI Thesaurus. Code C129406.

A protein family whose members form complexes with cyclin-dependent kinase 1 to form maturation promoting factor (mitosis promoting factor; MPF), which is essential for the progression through the G2/M and DNA damage cell cycle checkpoints. 